\title{
Preface
}

Not surprisingly for two economists, the motivations behind the writing of this book lie in our analysis of the demand and the supply of educational material on the European Union (EU). As for the demand side, the students of all ages and nationalities who attended in the last five years our graduate and post-graduate courses in EU-related subjects across several EU Universities and Institutions have been giving us two crystal-clear indications. First, over the years they showed a growing interest in EU policies and in the EU integration process. Second, however increasing this interest was, it was accompanied by a growing critical attitude towards what they perceived as unintelligible EU policy making. Such a critical attitude, in the best tradition of academia, translated into a growing will to understand the rationale (be it political or economic) behind such policies. As a consequence, our supply of educational material has been trying, over the years, to keep pace with the increasingly changing process of EU integration, trying at the same time to respond to these two clear indications. It was therefore natural, at a certain point, to gather all this material into the organic framework of a book.

The book has been written in about 18 months, between July 2003 and December 2004, building on the desire to explain the roots of the economics and policies of the European Union and the will to assess them critically in light of the deeply changed framework of the EU integration process. In particular, our enterprise has been stimulated by the fact that the EU has successfully completed three enormous projects that seemed pure wishful thinking only a few years ago: the Euro, the 2004 enlargement with ten new countries, eight of which lying on the eastern side of the now fallen Iron Curtain, and the signing of the EU Constitution in Rome on 29 October 2004. Indeed much of the energy behind the book is due to the fact that both of us have been working, with different and changing responsibilities within EU-based institutions, towards achieving these goals, since we both remain genuinely convinced of the necessity of pursuing the remarkable adventure initiated by the founding fathers of Europe.

We trust that the combination of factual explanation and of critical assessment characterising the book and capitalising on our academic background and our professional experience within the EU institutions renders the book valuable within the current panorama of publications on the same 
subjects. However it goes without saying that this book has been written in our personal capacity only, and, while we gratefully acknowledge the permission to publish granted by the European Commission, it does not engage whatsoever any of the institutions with which we have been interacting, solely representing our personal opinions.

Clearly, in the process of writing this book, many people have generously helped us in many and different ways. Although we feel equally indebted towards all of them, there are two persons whose continuous presence, help and encouragement have been determinant in imbuing us with the necessary skills and will for writing this book. One is Carlo Secchi, professor of European Economic Policy at Bocconi University (and Rector between 2000 and 2004): first our European affairs professor in our alma mater, then our mentor, supporter, professional guide and many things else. The other is André Sapir, Chief Economist of the Group of Policy Advisors of the EU Commission President (between 2001 and 2004), gentle, patient, generous and inspiring intellectual guide and human and professional example.

We are also indebted to the many people with whom we had the chance to confront, over the last ten years, many ideas and theses that now feature in this book. Some agreed with us, some did not, some convinced and charmed us, some were eventually convinced by us: at any rate, they all were extremely important in the elaboration of the ideas behind our work, and very generous in sharing their ideas with us. This list is very composite since it includes people of different positions, work, seniority and age (some are unfortunately not with us any longer). Hence we have decided to list them in strict alphabetical order: Philippe Aghion, Sergio Alessandrini, Roberto Artoni, Tassos Belessiotis, Massimo Bordignon, Renato Brunetta, Marco Buti, Angelo Cardani, Alessandra Casarico, Antonio de Lecea, Alex Ellis, Sylvie Goulard, Alexis Jacquemin, Mick Keen, Wilhelm Kohler, Jozef Konings, Richard Layard, Ricardo Levi, Erkki Liikanen, Maurice Marchand, Wim Moesen, Mario Monti, Francesco Passarelli, Lucio Pench, Jean Pisani-Ferry, Silvano Presa, Antonio Preto, Romano Prodi, Peer Ritter, Luis Romero, Riccardo Rovelli, Elena Saraceno, Michaela Schreyer, Leo Sleuwaegen, Peter Martin Smith, Alexander Stubb, Guido Tabellini, Alessandro Turrini, Johan Ureel, Reinhilde Veugelers, Helen Wallace, David Wright, Maurizio Zanardi . . and many, many others.

A special mention goes to the undergraduate and graduate students of Bocconi University and ISPI in Milan, who regularly lived through our courses or had their dissertation supervised by us: with their intellectual brilliance, they constituted a constant and fundamental source of stimuli for us, greatly contributing to the development of many of the analyses contained in this book.

We are particularly indebted to Stefano Riela, who jointly drafted with 
us the chapter of this book on competition policy and, together with Silvio Contessi, read different versions of our early drafts, providing us with very valuable contributions and suggestions. Pamela Cranston greatly helped us with the final formatting of the text.

Finally, but most importantly, we must thank our parents and siblings and Alexandra, Caterina, Olga, Silvia and Victoria, the five beautiful women of our lives who, with a broad palette of words, deeds and smiles, make each and every day worth living.

\section{NOTE TO THE INSTRUCTORS}

The book constitutes the material for a typical third-year undergraduate course in the economics of EU integration. In particular, the material is broadly organised in two parts. After an introductory chapter dealing with the very basic elements and key concepts of the European Union, from the Treaty of Rome to the European Constitution, the first part, covering Chapters 2 to 5 , presents the economic tools underlying the process of European integration: the theory of economic integration (Chapter 2), the economics of the Single Market (Chapter 3), the Economic and Monetary Union (Chapter 4), and the rationale of the process of structural reforms known as 'Lisbon strategy' (Chapter 5). The second part of the book, covering Chapters 6 to 10, deals instead with the main EU policies, starting with the budget (Chapter 6), then the expenditure policies of agriculture (Chapter 7) and cohesion and growth (Chapter 8), the competition policy (Chapter 9), and the EU external policy, with a particular focus on the World Trade Organisation (Chapter 10). Finally, Chapter 11 concludes with a discussion on the main challenges that lie ahead of the European Union.

In every chapter we have tried to offer a short historical perspective, the current state of evolution of the discussed instrument or policy, and the implications that the enlargement of the Union to 25 member states will have on the same instrument or policy in the years to come. To aid the reader, we have highlighted in bold new concepts or keywords every time we have discussed them for the first time. We have also tried to keep pace with the most recent evolutions of the EU integration process which are likely to shed their influence in the following years. In particular, in Chapter 1 the reader will find a schematic discussion of the innovations possibly introduced by the EU Constitution. The March 2005 reform of the Stability and Growth Pact is discussed in detail in Chapter 4, while the Commission's draft of the new EU Financial Perspectives for the period 2007-13 are presented in Chapter 6. Chapter 10 also introduces the latest 
evolutions in the Doha Round of negotiations at the World Trade Organisation.

On the basis of our experience, the material presented in the book can be exhaustively taught in approximately 64 hours (8 ECTS), equally shared between the economics part and the one dealing with policies. Less advanced versions of the course (6 ECTS, 48 hours) can be taught skipping the analysis of economies of scale in Chapter 2, the history and working of the European Monetary System in Chapter 3, the debates on the future of Economic and Monetary Union and its enlargement in Chapter 4, the controversy on the EU income distribution in Chapter 5, and the technical Appendixes and Boxes in Chapters 6 to 10, without compromising the general readability of the text. A very large set of accompanying slides, which can be used as teaching material, is available, on request, from the publishing house. 